\title{
SCHOOL DISTRICT TURNAROUND: LEADERSHIP DEVELOPMENT AS THE NEXUS OF CHANGE
}

\author{
Nadine Bonda, PhD \\ American International College \\ Eva Mitchell, MA \\ Doctoral student at University of Pennsylvania
}

\begin{abstract}
Context: Urban school districts have gone through countless reform efforts to no avail. The Massachusetts Department of Elementary and Secondary Education (ESE) has developed a model that has the potential to be a game changer in laying the foundation for student success.

Purpose: This article explores how one district used the model and targeted administrators as their nexus of change.

Intervention: ESE used a research-based approach to provide turnaround expertise and hold failing districts accountable for improvement. Each district was to develop and implement with support and monitoring, a plan known as the accelerated improvement plan, which became a blueprint for the change process.

Data Collection: Data was collected through monthly three-hour meetings and 12 full-day observations of instruction and meetings. Data was made public through quarterly progress reports posted on the ESE website and shared with the School Board and the public through local television.

Findings: The district chose to center their early change initiatives on building the capacity of school and district administrators. Critical to the plan's effectiveness was ongoing monitoring and feedback by ESE, since the failure of many change efforts is due to the inability of school districts to effectively self analyze and adjust practice which can lead to a lack of effective implementation.

Conclusions/Recommendations: The process mapped out an aligned "through-line" of changed routines and practices. Through-line is defined as changes at the district level resulting in changes at the school level, and, in turn, at the classroom level. Ultimately, that means that the lack of success at the student level is the result of insufficient improvement at the classroom level, the school level, and the district leadership and governance level. This
\end{abstract}


is a promising process that could lead to substantial improvement in student achievement in underperforming districts.

Keywords: Through-line, assistance, accountability, leadership, school effectiveness, increased student achievement

\section{Introduction}

In Massachusetts, many of the stories are the same: the old mill cities and towns where the mills are now empty, and an economy that once thrived are now struggling. These cities and towns are poor; a considerable percentage of their population is first generation American with a significant number of households speaking a language other than English. Here, many of the inhabitants live below the poverty line. These demographics impact their schools where large numbers of students are classified as low income; there is a sizable population of students classified as Limited English Proficient and First Language Not English. And their schools are often among the lowest performing schools in Massachusetts.

These school districts have tried several different approaches to turning around their failing schools. Administrators have written plan after plan, all with good intention, but also with few resources and a lack of turnaround expertise. The plans often end up on a shelf gathering dust.

This is the story of one such school district that while engaged with the Massachusetts Department of Elementary and Secondary Education (ESE) in a turnaround project focusing on increasing student achievement, capitalized on the assistance it received and began to build a stronger foundation for high student achievement than in previous attempts where they were provided with regulation but little to no support.

In 2011, the Massachusetts Department of Elementary and Secondary Education (ESE) took a new approach with five failing school districts. The districts are progressing at various speeds, but early indications are that the approach is taking hold in some districts. Although after almost three years of the process, there is not yet evidence of significant increased student achievement, there is evidence in each of the five districts that a foundation of good practice is being built at the district level and is filtering to schools and to classrooms. A through-line of urgency and improved practice can clearly be traced from the district, to the school, to the classroom, to the child.

\section{Why Report on Only One School District?}

Every school district is different - different demographics, different approaches to teaching and learning, different community beliefs about education. But every failing school district has something in common: its 
students are not learning at the rate the school, broader community, and society want. Examining one school district and documenting the progress made and the process used can serve to inform other school districts with similar challenges, about the numerous aspects of this change process that are working. Picking and choosing one or two techniques and applying them in isolation may not have a significant effect. But that does not mean that these techniques cannot inform other approaches. This carefully thought out system of improvement, based on the literature, and orchestrated by the MA State Department of Elementary and Secondary Education (ESE) has the potential to have a profound impact on schools. The school district, however, must embrace the process and use that process to build its own path toward needed student improvement.

\section{The Greater Educational Context}

Across the nation, there is a renewed focus on education. Policy leaders, government officials, and parents are calling for all school districts to guarantee that every school brings its students to high rates of proficiency. The public is no longer willing to accept excuses for why our children cannot learn. In turn, schools must guarantee the public that each child receives the kind of individualized and directed instruction that will lead to proficiency in all core subjects, but particularly in math and English. In order for all districts to produce this result, but especially those in urban and low-income communities, they must evolve. They must become high-performing organizations that use the most current, research-based best practices. They must be continuously improving organizations that can adjust to rapid changes to circumstances, funding, demographics, staff turnover, and new research. And these districts must differentiate funding, support, and strategies between and among schools and students in order to provide attention to individual and unique needs. Layered onto the school district profile is that these districts must adhere to governmental regulation, are highly politicized, and often unionized, with long-standing histories and deeply embedded traditions. State Education Authorities (SEAs), which include child protection agencies, safety regulation agencies, building authorities, educator licensure regulators, funding authorities, curriculum officials, to mention a few, must, in turn, respond by supporting districts in being high-performing and continuously improving organizations by using research-based best practice to define what successful schools and districts look like, and by providing targeted support to help districts attain the highest standard. Support needs to be re-envisioned to meet the differentiated needs of these school districts and the schools within them. 


\section{The Massachusetts Context}

The Massachusetts Department of Elementary and Secondary Education has a definition of a high-performing school district articulated as six District Standards for systems of: leadership and governance, curriculum and instruction, assessment and data use, human resources and educator development, student support, and financial and asset management. Each of the six standards is defined generally and contains three to five researchbased indicators of best practice. These standards have been evolving since 2003 and are used by ESE's Center for District and School Accountability as the basis for a district self-assessment and a qualitative review of district practice using a protocol. These documents are available on the ESE website at (http://www.doe.mass.edu/apa/general/).

ESE also has developed an aligned set of Conditions for School Effectiveness with a school level self-assessment. However, the theory of action for ESE has evolved and after working directly with schools in the past has now made the strategic decision that the district is the focal point, as it has responsibility for ensuring the success of all of its schools. School improvement activities by ESE now focus on building district capacity to lead school improvement work, rather than have districts rely solely on the direction that ESE might take. This allows districts and school within the district to assess their own needs and their capacity for moving forward in a particular direction over a defined time period with an effort that can reach all schools in the district. This theory of action also undergirds ESE's Framework for Accountability and Assistance, which assigns a level 1-5 for each school and district. The district's level is determined by the levels of its schools, and can be placed in the highest levels of need (Level 4 and 5) as a result of a district review demonstrating that systems (related to the District Standards discussed above) are insufficient for supporting its schools effectively.

For districts at Level 4, the ESE began in 2010 developing an approach to accelerating improvements to district practice and student achievement through an Accelerated Improvement Planning and Implementation process (http://www.doe.mass.edu/apa/sss/turnaround/). This process was developed to support districts in becoming a continuously improving organization, in order to rapidly make traction in becoming a high-performing organization. The Accelerated Improvement Plan (AIP) and the process were created initially through a partnership between ESE and Cambridge Education, a consulting company, which had documented success in turning around the lowest-performing district in Islington, England from 2005 - 2012 (Dibb, 2012). This process in Massachusetts continues to evolve based on developing research pertaining to district 
improvement. Foundational texts that contributed to the formation of this ESE model can be found in the reference list.

\section{Two Pronged Approach: Assistance, Accountability}

Failing school districts are often encumbered with practices, rituals, politics, culture, and contracts that keep them on a steady path toward underperformance. Often this cycle needs to be broken in order to see progress. The research-based approach developed by ESE was to provide turnaround expertise while at the same time holding the district accountable monthly for making significant change.

Each district was given the funds and the support to hire a Plan Manager who was an expert in district and school turnaround. Some of these Plan Managers had the support of a company or network behind them. The job of the Plan Manager was to help the district write a plan, called an Accelerated Improvement Plan (AIP), and then support the district in the implementation of that plan. Hiring the right company or consultant to design, manage, and coach the change initiatives was an extremely important first step. Companies and consultants were vetted by ESE, but hired by the district. The Plan Manager, who agreed to be in the district initially a minimum of two days per week, answered directly to the Superintendent. The first order of business for these districts was to get systems in place that would ultimately lead to higher student achievement.

ESE also recognized that the adage of "what gets measured gets done," must come into play to ensure accountability. If the Department of Elementary and Secondary Education was going to invest significant funding in these districts, it wanted assurance that research-based changes would be initiated and would become embedded in the practices of the district. Consequently, each district was assigned a Plan Monitor. The team of Plan Monitors reviewed the AIPs, provided feedback to the districts, and once ESE accepted the plan, monitored its implementation. The Plan Monitor assigned to the district wrote quarterly progress reports that went to the Superintendent and School Board and presented those reports at a public and locally televised School Board meeting. As well, once a year, the Plan Monitor wrote a summary report for the State Board of Education.

\section{The Accelerated Improvement Plan}

The plan that the district was required to write, the Accelerated Improvement Plan, became a blueprint for the change process over the next two years. The plan is based on the premise that if the district "can define a narrow set of strategic objectives to accelerate student learning, execute well-defined initiatives with a relentless focus on implementation, and systematically monitor the impact of those initiatives to inform mid-course 
corrections, outcomes for students will be dramatically transformed" (Massachusetts Department of Elementary and Secondary Education, 2013). The plan focused on the three to five important goals that the district would spend its energies on. For each goal, or Strategic Objective, as they are called in the AIP, the district defines 3-5 objectives that have the potential to lead to the accomplishment of the Strategic Objective. For each objective, there needed to be a set of specific, measurable benchmarks that the district must accomplish. Benchmarks fall into three categories: early evidence of change, short-term outcomes, and final outcomes. Final outcomes were based on state-developed goals for student improvement. For each objective, the district defined a set of actions to accomplish that objective and attributed responsibility to an individual in the district.

To prepare for the Quarterly Progress Reports (QPR), the Plan Monitor held monthly Highlight Meetings, facilitated by the Plan Manager. The monthly highlight meetings might include, aside from the Superintendent and Plan Manager, the assistant superintendent(s), principals, directors, the Superintendent's mentor, the union president, or other personnel as seen appropriate by the Superintendent, Plan manager, or Plan Monitor for that particular meeting. At the monthly highlight meeting, the district discussed the progress it had made during the last month, as well as obstacles encountered and ways to mitigate those obstacles. The district also presented the Plan Monitor with any data aligned to the AIP that demonstrated progress on meeting any benchmark that month.

\section{Methodology}

The methodology employed in this research was a basic qualitative method. Qualitative research, as defined by Merriam (2009) includes four major characteristics: a focus on understanding the meaning of an experience, the researcher as the primary instrument for data collection and analysis, the process allowing the researcher to build theory from observations and understandings, and a richly descriptive end product. The primary researchers in this project were the plan monitor and the Associate Commissioner for the Center for District and School Accountability at ESE. The Plan Monitor collected the data and both did the analysis.

In order to write the quarterly progress reports, the Plan Monitor gathered information presented at each monthly highlight meeting. This included descriptive data of the initiatives that were undertaken and their progress, as well as baseline and follow-up data from multiple sources including benchmark and summative testing. Other data might include, depending upon the focus of the Strategic Objectives, attendance, failure rates, disciplinary actions, data gathered during teacher observations, evidence of professional development enacted in the classroom to improve 
performance, or data kept by principals and directors on their practice, among other numerous sources of data. In order to triangulate the data, the Plan Monitor spent one or more days in the district each quarter, observing classes, having meetings with teachers, administrators and parents, watching conferencing opportunities between administrators or administrator and teacher, attending district or school planning meetings, and observing professional development opportunities for teachers and/or administrators. In total, the plan monitor interviewed the superintendent, the assistant superintendent, every principal, and all other central office administrators who worked on the turnaround project. As well, she interviewed the team members from the consulting firm that coordinated the project. This amounted to well over 30 individuals, some interviewed several times. The researchers transcribed each transcript, coded all data, and searched for patterns in order to organize similarly coded data into categories (Merriam, 2009). The researchers then created sub-categories where needed. After the coding was complete, the researchers organized and combined categories and compared this data with the additional data described in the above section in order to generate themes that synthesized the findings.

\section{The Through-line}

The ultimate goal of the work in each of the districts was to create a through-line from work at the district level to work with principals and other administrators, who would then bring important changes to each classroom in every school. The district was then held accountable for increased student achievement. The Progress and Performance Index (PPI), which is a measure of the district, school, and group progress in narrowing proficiency gaps, determines the benchmark for student achievement in Massachusetts's schools. Groups are defined as low income, special education, former/English language learner, or one of seven racial/ethnic categories. The Department of Elementary and Secondary Education determines the PPI for each school district. The PPI is the ultimate benchmark for the school district.

\section{One District's Journey}

Mill City, a pseudonym, had been at this work of systemic change for many years. District leaders created plan after plan and still Mill City was the lowest performing school district in Massachusetts. In fact, there are many shelves in Mill City filled with old plans. Some of these plans resulted in small changes, but nothing that had the potential to change the culture. Culture can mean many things: as Deal and Kennedy once wrote, it is the way things get done around here (Deal \& Kennedy, 1982), but it can also mean the willingness to change (Hargreaves, 1997). 
States cannot afford to tinker in their efforts to address low district performance. As Tyack and Cuban asserted, "drawing on the twin themes of utopia and tinkering, we suggest reformers take a broader view at the aims that should guide public education and focus on ways to improve instruction from the inside out rather from the top down” (Tyack \& Cuban, 1995, p. 143). Failing districts also cannot afford to tinker with turnaround efforts. They need to have a comprehensive plan that will affect all parts of the school system and will place teaching and learning at the center of districtwide improvement. The long history of ESE's failed turnaround efforts in Mill City since 1993 could be called "tinkering." Reform efforts did not go far enough to achieve results. After a decade of interventions, costing the state millions of dollars, Mill City still was among the lowest performing districts in Massachusetts.

As described previously, the Accelerated Improvement Plan (AIP) was designed to go deeper, and represent a district partnership with ESE. For their new AIP, Mill City chose three strategic objectives. One objective was a curriculum objective aimed at increasing teacher capacity. The other two objectives were to:

- Improve instructional quality by building leadership capacity throughout the district to continuously improve teaching and learning.

- Foster a cycle of continuous improvement and accountability by using data to effectively examine and improve teaching and learning.

Mill City started in the place that they thought could bring about the biggest change. If their administrators were more knowledgeable and could bring their new knowledge to classrooms, the through-line from district to school to classroom could be created. The first action plans included forming a District Instructional Leadership Team (DILT), consisting of all administrators in the district. That team met for an entire day each month for directed professional development. What the district leaders learned, they were expected to bring back to their schools and implement. For example, they were expected to guide their school leadership teams in developing a School Improvement Plan that followed directly from the AIP. As well, they were learning how to collect data, analyze it, and interpret that data into meaningful steps for improvement. Principals were expected to model the use of data in faculty meetings, committee meetings, and one-on-one discussions with teachers. Principals received support in their implementation efforts and were closely monitored by the Superintendent and Assistant Superintendent. From 2011-2013, the Assistant Superintendent met with each principal monthly to discuss progress on his or her School Improvement Plan. 
The momentum generated by the Accelerated Improvement Plan came from three major factors:

1. Time and energy was put in at the beginning of the process to build a district-wide sense of urgency and focus on the AIP.

2. Every administrator had a role in designing the plan for accomplishing the AIP, which built commitment to the goals of the AIP.

3. The plan took a systemic approach that was clearly laid out at the beginning of the process.

The initial focus of the AIP was to work with administrators to get them on board with the AIP process and to build their skills. Skill building was done through intensive professional development monthly for two years and was planned to continue into the third year. A DILT planning committee, with representation from principals and district level administrators, carefully planned these meetings. The Plan Manager helped to give structure to the meetings and provide the needed professional development. The Plan Manager built into the professional development numerous ways to develop leadership skills. For example, a different administrator each month was responsible for running the DILT, making sure that each segment ran on time and those responsible for each segment were prepared.

Topics in the first year started with how to build a School Improvement Plan that was aligned to the AIP, and continued to include topics such as understanding what rigorous instruction is and recognizing it in the classroom, doing effective walkthroughs of classrooms followed by constructive feedback to teachers, monitoring teacher progress in increasing achievement of students in their classes, having difficult conversations with teachers about how best to improve their practice, using and modeling for the use of others data to support instruction, and strengthening core curriculum, particularly math and English. In addition, administrators were called upon to make their practices more public to the DILT.

\section{Making practices public}

Each administrator was taught how to do effective classroom walkthroughs. The administrators developed a tool that included a list of important instructional strategies and room for comment after each strategy, a copy of the results of which went into the teacher's mailbox that day, so that teachers were getting immediate feedback. Additionally, each administrator was given a target number of walkthroughs to do each month. That data was reported to the Assistant Superintendent and she included it in the material packet for each monthly DILT meeting. 
Administrators learned how to self-reflect. They were given a threelevel rubric, highly effective, effective, improvement necessary, in four standards: leadership, continuous improvement, rigor, and data. Each month, they rated themselves in the four standards and provided a rationale for that rating along with next steps for their continued improvement. Again, those results appeared in the DILT packets for all administrators to see.

Each month each principal met individually with the Superintendent and/or the Assistant Superintendent to review the School Improvement Plan (SIP). At these meetings principals brought with them a color-coded copy of their SIP reflecting items that were complete, in progress, or had no action. As well, prior to each meeting, the principal was to reflect, assess, and color code their progress for each standard on the self-assessment rubric. They needed to identify the areas they were still working on, provide evidence to support the scores, set a goal for what they would achieve the next month, and specify the steps they would take to achieve the goal. The results of the self-assessment rubrics were reported in the monthly DILT materials. A memo to the principal followed each meeting reviewing the salient points that were discussed in the meeting, the decisions made, and areas for the principal to improve on.

Making their practices public, at least to the group of administrators, was not something that principals had prior experience with. Those who embraced the idea began to talk more openly about their practice and seek ideas from colleagues on how to improve it.

\section{Intensive Feedback to Administrators}

Principals received ongoing feedback from the Superintendent and Assistant Superintendent. The monthly meetings with individual principals were rigorous. Principals were expected to come prepared and ready to explain their practice over the previous month. They learned how to collect and display data to show their progress as a leader and their schools' progress toward increasing student achievement.

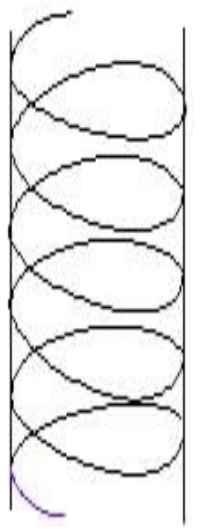

The Assistant Superintendent also frequently visited schools and did walkthroughs with principals. The principal would then sit with the Assistant Superintendent to discuss the instruction they saw, the areas for improvement, and then be expected to write a memo to the Assistant Superintendent outlining their plan for instructional improvement. 


\section{Steps for Systemic Change}

- Change at the school and classroom level

- Intensive feedback to Principals

- Monitor new practices of Principals

- Supervision to Support Principals' change of practice

- Support for Principals to implement professional development in their buildings

- Professional development for Principals

- District level planning

\section{Accelerated Improvement Plan}

The illustration demonstrates the throughline from district planning to change in instruction that directly affects student learning.

\section{Concentrating on Leadership as the Nexus for Change}

This model of change recognizes that the driving force within a district is a leader who has an understanding of how to develop a systematic change process within a district and within a school. Principals were given intensive professional development. They were then expected to implement components of that professional development in their own schools. Principals were supported throughout the process by the Superintendent, Assistant Superintendent, and Plan Manager. However, critical to the effectiveness of this model was monitoring, since the failure of many change efforts is due to the lack of follow-through and assessment of the effectiveness of implementation. Principals were monitored by the Superintendent and Assistant Superintendent in their planning, their execution of the plan, and their observations and feedback to teachers. Practices were made public and intensive feedback was provided to principals to help hone their practices. This process is intensive and relentless. The Plan Monitor assigned by ESE monitored at least monthly the Superintendent and Assistant Superintendent. Practices are changing in this school district. A foundation for improved student achievement is being laid. The district has not yet achieved its goals, but the process is a promising one that could lead to substantial improvement in student achievement in a district that has had little success in this area over many years.

\section{Organizational Analysis}

As the case study describes, the Massachusetts' two-pronged approach with assistance and accountability has led to the district's development of a promising Accelerated Improvement Plan focused on three strategic objectives that form a "through-line" between leadership and 
educator development in the classroom to improve instructional quality, use data effectively, and focus on literacy. Momentum was generated because the district had made effective decisions to upfront the focused planning work with a sense of urgency, include administrators in developing and taking responsibility for executing the AIP, and ensuring that there was a clear systematic implementation strategy. Everything about the AIP was public and involved intensive feedback-teachers had open classrooms; principals had open buildings and public school improvement plans; district leaders had outcomes to meet; and School Board members received quarterly progress reports. These efforts resulted in systemic changes, and leadership was identified as the nexus of the change.

However, the improvements in systems and practices have not yet led to clear results in student achievement. This analysis is an effort to understand what should take place next in Mill City Public Schools. First we will analyze the role of the state-the leverage and the limitations of the SEA's capacity to generate improvement in a school district. Then we will analyze the district's capacity to generate improvement given the local educational and political context in which it must operate.

\section{Analysis of the State Role}

The state can be a central actor in improving educational practices but this work can take quite some time- even decades — and during this time the role of the state needs to be multifaceted, including changes to policy, influence on media messages, and promotion of public and professional discourse (Russell, 2010). The AIP process is designed to promote a continuous cycle of improvement from the governance level, to the central office level, to the school level, to the classroom level, in order to create what Schlechty (2009) calls a "learning organization.” AIPs work to break through change resistance through several steps: working with districts to develop effective improvement plans; supporting district capacity-building by providing ESE-funded, part-time Plan Managers; celebrating success achieved through new internal monitoring structures (developed in partnership with the district with the support of Plan Managers); providing objective information through external monitoring (including monthly site visits and data collection conducted by Plan Monitors); and quarterly public accountability reporting on the district's progress (during School Board meetings). Monitoring depends on valid and reliable self-reporting, and is useful only if the information about implementation effectiveness informs mid-course corrections. 
The standards for the AIP ${ }^{9}$ presume, as Meyer and Rowan (2003) do, that rapid change is promoted more by shifts in "environmental categories" than instructional changes in isolation, because they determine priorities. Meyer and Rowan find that "The formal structure of an organization is in good part a social myth and functions as a myth whatever its actual implementation” (2003, pg. 210). The formal structure is tied to ideology rather than results (Meyer \& Rowan, 2003). The AIP is an attempt to change that. The AIP process couples an evaluation of district practices with the outcomes it receives. This is different from the typical U.S. practice; while other countries more frequently engage in a rigorous educational inspection system, in the United States, accountability has been mostly limited to testing (Meyer \& Rowan, 2003). As the authors point out, coupling practice and outcomes can undermine the logic of confidence. After all, traditionally "a school's formal structure (its ritual classifications) is 'decoupled' from technical activities and outcomes” (Meyer \& Rowan, 2003, p. 221).

\section{District-State Interface}

Even in the face of change agents, such as the AIP with its coupling of practices and results, school districts have an isomorphic tendency. The term "isomorphic" is a term used in science and mathematics meaning being similar in structure. DiMaggio and Powell (1983) describe institutional isomorphism in the face of three types of change mechanisms-coercive, mimetic, and normative. All three are employed in the SEA's AIP process, so Mill City's change resistance can be observed under this framework.

Coercive authority is exercised by the SEA when the state declares the district "Level 4/underperforming" and requires it to develop an AIP using a specific template, and requires it to participate in monitoring activities.

Normative authority is exercised in these ways: the Plan Monitor observes district practice and has conversations with district and school leaders concerning evidence of implementation, state leaders join the Plan Monitor in School Board meetings to discuss quarterly progress reports, and these reports may then be used in conversations with the state Board of Education as well as elected state leaders. The SEA is defining what is appropriate practice and shifting the dominant voices.

Mimetic authority is also exercised in more subtle ways - the monitor questions in monthly site visits the degree to which traditional district practices are working, and Plan Managers are assigned with the

\footnotetext{
${ }^{9}$ The five criteria for the AIP are outlined in a rubric used by the Department to assess each plan priori to approval. The criteria are: provides focus; promotes rapid improvement to teaching and learning; addresses systemic weaknesses; builds long-term capacity; and useful for measuring progress.
} 
responsibility of pushing for changes to systems and routines that structure behavior. The authors argue that,

Without constant monitoring individuals pursuing parochial organizational or subunit interests can quickly undo the work... despite superior resources and sanctioning power, organizational elites are often unable to maximize their preferences because 'the complexity of modern organizations makes control difficult.' Moreover, organizations have increasingly become the vehicle for numerous 'gratifications, necessities, and preferences so that many groups within and without the organization seek to use it for ends that restrict the return to masters. (Perrow as cited in DiMaggio and Powell, 1983, p. 157)

However, the multiple processes occurring at the highest levels and at the subunit levels are difficult to monitor not only because they are numerous and complex but because (1) political decision-making is a hard-to-detect actor and (2) leadership's tendency to avoid evaluation and inspection of their educational systems.

First take the issue of political decision-making. Meyer and Rowan note that,

In the United States the legitimacy of local control in some measure de-professionalizes school administrators at all levels... They do not carry with them the authority of the central, national, professional, and bureaucratic structures and the elaborate ideological backing that comes with it. American administrators must compromise and must further lose purely professional authority by acknowledging their compromised role. They do not have tenure, and their survival is dependent on laypersons in the community, not professionals. (Meyer and Rowan, 2003, p. 221)

Operating in this political system often involves the avoidance of close inspection. Reasons for avoiding close inspection include: (1) complicity and satisfaction of staff, (2) the tendency to disassociate educational value with the efficiency of instructional activities or learning achieved per dollar, (3) increased technical uncertainty at the local level arising from state and federal expectations, and (4) provision of a buffer for inconsistencies that might otherwise need addressing — but might create conflict. "When the behavior of teachers and students is uninspected or located in isolated classrooms, the state, the community, and administrators are presented with little evidence of ineffectiveness, conflict, or inconsistency" (Meyer and Rowan, 2003, p. 207). As Meyer and Rowan recognize, the avoidance of monitoring is rational: "Consider this matter from the viewpoint of any rational college president or school superintendent. The whole school will dissolve in conflict and illegitimacy if 
the internal and external understanding if its accredited status is in doubt" (Meyer and Rowan, 2003, p. 203). The stakes are certainly high:

With the confidence of the state bureaucracy, the federal government, the community, the profession, the pupils and their families, and the teachers themselves, the legitimacy of the school as a social reality can be maintained. However, if these groups decide that a school's ritual classifications are a 'fraud,' everything comes apart. (Meyer and Rowan, 2003, p. 205)

\section{District Organizational Learning and Coupling Practice with Results}

The stated purpose of the AIP is to support more effective and informed district-decision making. Critically important to district improvement are organizational learning, role development, and increased capacity at the district central office level for implementing improvement initiatives effectively and supporting fidelity of practice and outcomes (Honig, 2003).

Meyer and Rowan explain Goffman's idea of “'face work' - the process of maintaining the others' face identity and thus maintaining the plausibility and legitimacy of the organization (Meyer and Rowan, 2003). They argue that decoupling school structures and their results (in terms of adult practice and student outcomes) leads to what Goffman describes as “avoidance, discretion, and overlooking” (Meyer and Rowan, 2003, p. 207).

The AIP was designed to couple systemic changes, to changes in adult practice, to changes in student performance - the throughline. Each objective must also contain benchmarks of success of two types: changes to student performance (short term outcomes), and changes for adult behavior or practice (early evidence of change). Evidence must be collected to demonstrate that the district has met its benchmarks. The benchmark data is collected to determine both whether the plan is being implemented in ways that change routines (measurable changes to adult behavior are called early evidence of change benchmarks in the AIP), as well as correlation with student performance outcomes (these are called short term outcomes in the AIP). Early evidence of change benchmarks redefines what is appropriate teacher behavior. Success in meeting early evidence of change or short-term outcomes redefines the way performance is legitimized. This process is an attempt to support the development of a renewed organizational code to socialize individuals to incorporate new practices. Some early evidence of change benchmarks are also designed to determine changes in the ethosdistricts collecting survey data is one example. The AIP process of collecting data about school-level implementation, ensuring an effective response, and putting in practice supports by the central office level is critical. Chronicled in a well-known case study, Baltimore Public Schools used data to 
reinterpret the historical practices of the organization, to identify new targets, and to provide more understanding of the current level of practice, and therefore, what change is necessary (Grossman, Johnson \& Brookover, 2011). This study gives credence to the process that the ESE is pursuing.

\section{Summary}

In an effort to develop a strong foundation of introspection in schools, the Department of Elementary and Secondary Education (ESE) engaged initially with five school districts in a turnaround project focusing on increasing student achievement. This paper documents the journey of one poor, urban school district that capitalized on the assistance it received and began to build a stronger foundation for high student achievement by using leadership as the nexus for change. It began its work by developing an Accelerated Improvement Plan that defined three strategic objectives. Initiatives and the component activities in the AIP were designed to map out an aligned "throughline" of changed routines and practices at each level in the system. In practice, the throughline means that changes at the district level result in changes to the school level, and in turn to the classroom level. Ultimately, that means that the lack of success at the student level is the result of insufficient improvement at the classroom level, and insufficient improvement at the school level, and also insufficient improvement at the district leadership and governance level. This notion interferes with the "logic of confidence" at multiple levels. It also recognizes the challenge of change because there are multiple players (Schlechty, 2009).

\section{What Next?}

Mill City is now in year four of this process. This is the year that it is expected that Mill City will demonstrate whether that throughline has occurred, and the strength of that throughline. School districts are not static organizations: the players change, new ideas are introduced, new pathways are taken. However, in Mill City a foundation was laid that was based on research and the best ideas available. And change started with a focus on developing school leaders to take a new kind of leadership in their schools. For our schools to improve, particularly our urban areas, we need to be putting in place those best ideas and documenting their implementation.

\section{References:}

DiMaggio, P. \& Powell W.W. (1983). The Iron Cage Revisited: Institutional Isomorphism and Collective Rationality. American Sociological Review, 48(2) 147-160.

Dibb, J. (2012). Islington's education turnaround. Retrieved from http://www.guardian.co.uk/teacher-network/2012/feb/15/ 
Edmonson, A. (2012). Teaming: How organizations learn, innovate, and compete in the knowledge economy. San Francisco: Jossey-Bass.

Elmore, R. (2006). Learning by Doing: A Handbook for Professional Learning Communities at Work. Indiana: Solution Tree.

Fullan, M. (2010). All systems go: The change imperative for whole system reform. Thousand Oaks, CA: Corwin Press.

Grossman, A., Johnson, S.M. \& Brookover, E. (2011). Baltimore City Public Schools: Implementing Bounded Autonomy. Public Education Leadership Project at Harvard University, PEL-063.

Hargreaves, A. (1997). Rethinking educational change with heart and mind: 1997 ASCD yearbook. Virginia: Association for Supervision and Curriculum Development.

Honig, M.I. (2003). Building Policy from Practice: District Central Office Administrators' Roles and Capacity for Implementing Collaborative Education Policy. Educational Administration Quarterly, 39(3): 292-338.

Kegan, R., \& Laskow Lahey, L. (2009). Immunity to change: How to overcome it and unlock the potential in yourself and your organization. Boston: Harvard Business Press.

Levitt, B. \& March, J.G. (1988). Organizational Learning. Annual Review of Sociology, 14:319-340.

March, J.G. (1991). Exploration and Exploitation in Organizational Learning. Organizations Science, 2(1): 71-87.

Massachusetts Department of Elementary and Secondary Education (2013). Guidance for level 4 districts: Focused planning for accelerating student Learning. Boston: Massachusetts Department of Elementary and Secondary Education

Massachusetts Department of Elementary and Secondary Education (2013). Accountability reports: Accelerated improvement plans for districts into level 4. Retrieved from http://www.doe.mass.edu/news/news.aspx?id=7210 Merriam, S. R. (2009). Qualitative research: A guide to design and implementation. San Francisco, CA: Jossey-Bass.

Meyer, J.W., \& Rowan, B. (2003). The Structure of Educational Organizations. In J.H. Ballantine \& J. Z. Spade (Eds.). Schools and Society: A Sociological Approach to Education. Second Edition (pp. 201-212). Canada: Wadsworth Publishing. (Originally published in 1978.)

Russell, J.L. (2011). From Child's Garden to Academic Press: The Role of Shifting Institutional Logics in Redefining Kindergarten Education. American Educational Research Journal, 48(2): 236-267.

Schlechty, P.C. (2009). Leading for Learning: How to Transform Schools into Learning Organizations. San Francisco, CA: Jossey-Bass.

Schlechty, P.C. (1993). On the Frontier of School Reform with Trailblazers, Pioneers, and Settlers. Journal of Staff Development, 14 (4): 46-52. 
Tyack, D. \& Cuban, L. (1995). Tinkering towards utopia. Cambridge: Harvard Education Press.

Zavadsky, H. (2012). School turnarounds: The essential role of districts. Cambridge: Harvard Education Press. 